\title{
An ecosystem service approach to support integrated pond management: A case study using Bayesian belief networks - Highlighting opportunities and risks
}

\author{
Dries Landuyt ${ }^{\text {a, b, * }}$, Pieter Lemmens ${ }^{c}$, Rob D'hondt ${ }^{b}$, Steven Broekx ${ }^{a}$, Inge Liekens ${ }^{a}$, \\ Tom De Bie ${ }^{c}$, Steven A.J. Declerck ${ }^{c, d}$, Luc De Meester ${ }^{c}$, Peter L.M. Goethals ${ }^{b}$ \\ ${ }^{a}$ Unit Environmental Modelling-RMA, Flemish Institute for Technological Research (VITO), Boeretang 200, B-2400 Mol, Belgium \\ ${ }^{\mathrm{b}}$ Laboratory of Environmental Toxicology and Aquatic Ecology, Ghent University, Jozef Plateaustraat 22, B-9000 Ghent, Belgium \\ ${ }^{\mathrm{c}}$ Laboratory of Aquatic Ecology, Evolutionary Biology and Conservation, KU Leuven, Charles Deberiotstraat 32, B-3000 Leuven, Belgium \\ ${ }^{\mathrm{d}}$ Department of Aquatic Ecology, Netherlands Institute of Ecology (NIOO-KNAW), Postbus 50, 6700 AB Wageningen, The Netherlands
}

\section{A R T I C L E I N F O}

\section{Article history:}

Received 12 May 2014

Accepted 17 June 2014

Available online

\section{Keywords:}

BBN

Cost-benefit analysis

Risk assessment

Scenario analysis

Decision support system

\begin{abstract}
A B S T R A C T
Freshwater ponds deliver a broad range of ecosystem services (ESS). Taking into account this broad range of services to attain cost-effective ESS delivery is an important challenge facing integrated pond management.

To assess the strengths and weaknesses of an ESS approach to support decisions in integrated pond management, we applied it on a small case study in Flanders, Belgium.

A Bayesian belief network model was developed to assess ESS delivery under three alternative pond management scenarios: intensive fish farming (IFF), extensive fish farming (EFF) and nature conservation management (NCM). A probabilistic cost-benefit analysis was performed that includes both costs associated with pond management practices and benefits associated with ESS delivery.

Whether or not a particular ESS is included in the analysis affects the identification of the most preferable management scenario by the model. Assessing the delivery of a more complete set of ecosystem services tends to shift the results away from intensive management to more biodiversityoriented management scenarios.

The proposed methodology illustrates the potential of Bayesian belief networks. BBNs facilitate knowledge integration and their modular nature encourages future model expansion to more encompassing sets of services. Yet, we also illustrate the key weaknesses of such exercises, being that the choice whether or not to include a particular ecosystem service may determine the suggested optimal management practice.
\end{abstract}

(C) 2014 Elsevier Ltd. All rights reserved.

\section{Introduction}

Freshwater ponds are multi-functional ecosystems that provide a broad set of social, ecological and economic benefits for human well-being (IUCN, 1997; Bekefi and Varadi, 2007; EPCN, 2007; Downing, 2010). These benefits are collectively referred to as ecosystem services (Daily, 1997; MEA, 2005). Typical services of pond systems include fish production, water supply, nutrient

\footnotetext{
* Corresponding author. Laboratory of Environmental Toxicology and Aquatic Ecology, Ghent University, Jozef Plateaustraat 22, B-9000 Ghent, Belgium. Tel.: +329264 3996.

E-mail address: dries.landuyt@ugent.be (D. Landuyt).
}

retention, carbon sequestration, biodiversity and recreational use (EPCN, 2007). Despite the high potential of ponds for the provisioning of multiple services, evaluations of management practices typically focus on a limited number of services, such as fish production, whereas other benefits are frequently overlooked (Pechar, 2000). More recently, the awareness of the importance of social and ecological aspects of pond management is rapidly growing, amongst others through the implementation of the common fisheries policy of the European Union, which strives toward sustainable aquaculture, and the Strategic Plan for Biodiversity 2011-2020, which aims to stop biodiversity loss by 2020 (UNEP/ CBD, 2010). Currently, there is a strong need to take into account the multi-functionality of pond ecosystems during the development of management plans. Models and decision support tools are 
useful instruments to guide the development of such management plans. Although several studies have been conducted on multifunctionality of pond systems (Céréghino et al., 2010; Kloskowski, 2011), integration of this multi-disciplinary knowledge into practical management suggestions is rarely done.

In the past, several decision support systems have been specifically designed to aid the development of management programs for freshwater ponds and lakes (e.g. Gawne et al., 2012; GutiérrezEstrada et al., 2012). Although these tools have proven to be promising in suggesting alternative management practices during adaptive pond management, they generally focus only on one or a very limited number of objectives. The majority of benefits, especially the less tangible ones, are frequently omitted, which may lead to wrong, ill-informed decisions. An approach that takes into account ecosystem services (ESS), as mentioned by Soto et al. (2008), can tackle this problem due to its ability to identify, model and assess a more encompassing set of benefits associated with ecosystems. This can guide pond management toward a more balanced delivery of economic, social and ecological benefits, where benefits are optimized and trade-offs between benefits are revealed. Costbenefit analysis (CBA) is a convenient method to put the ESS approach into practice (Newton et al. 2012). CBAs include both costs associated with management practices and benefits associated with ESS delivery. As the benefits of ESS delivery can be expressed in monetary terms (Costanza et al., 1997), costs and benefits can be compared directly and management decisions can be optimized toward more cost-effective ESS delivery. These CBAs have been referred to as environmental CBAs by Atkinson and Mourato (2008). As management of natural systems is inextricably linked with uncertainties, knowledge on the uncertainties associated with particular management outcomes is valuable and should be taken into account in CBAs (e.g. Bianchini and Hewage, 2012; Karmperis et al. 2012). Research of Newton et al. (2012) indicates that calculated net benefits can be highly sensitive to market price fluctuations. Although the importance of risks in environmental management is widely recognized, explicit consideration of uncertainties in environmental CBAs is currently limited (e.g. Ticehurst et al., 2007; Barton et al., 2008).

This paper discusses a methodology to perform an environmental, probabilistic CBA to assess the effect of different pond management practices on ESS delivery, and analyses the effect of taking more/less putative ecosystem services into account. As the outcome of such CBAs may strongly depend on the type and number of ESS taken into account, we assessed the sensitivity of the CBA outcomes on including or excluding particular services into the analysis. For this purpose, a Bayesian belief network (BBN) model was developed to model ecosystem functioning and service delivery of a single pond. This study focusses both on the potential of BBNs to facilitate cross-disciplinary communication for knowledge integration as well as on the sensitivity of ESS assessments to the set of services taken into account.

\section{Methods}

\subsection{Study area}

The pond complex 'Vijvergebied Midden-Limburg', located in the north-eastern part of Belgium (Fig. 1), was selected as study

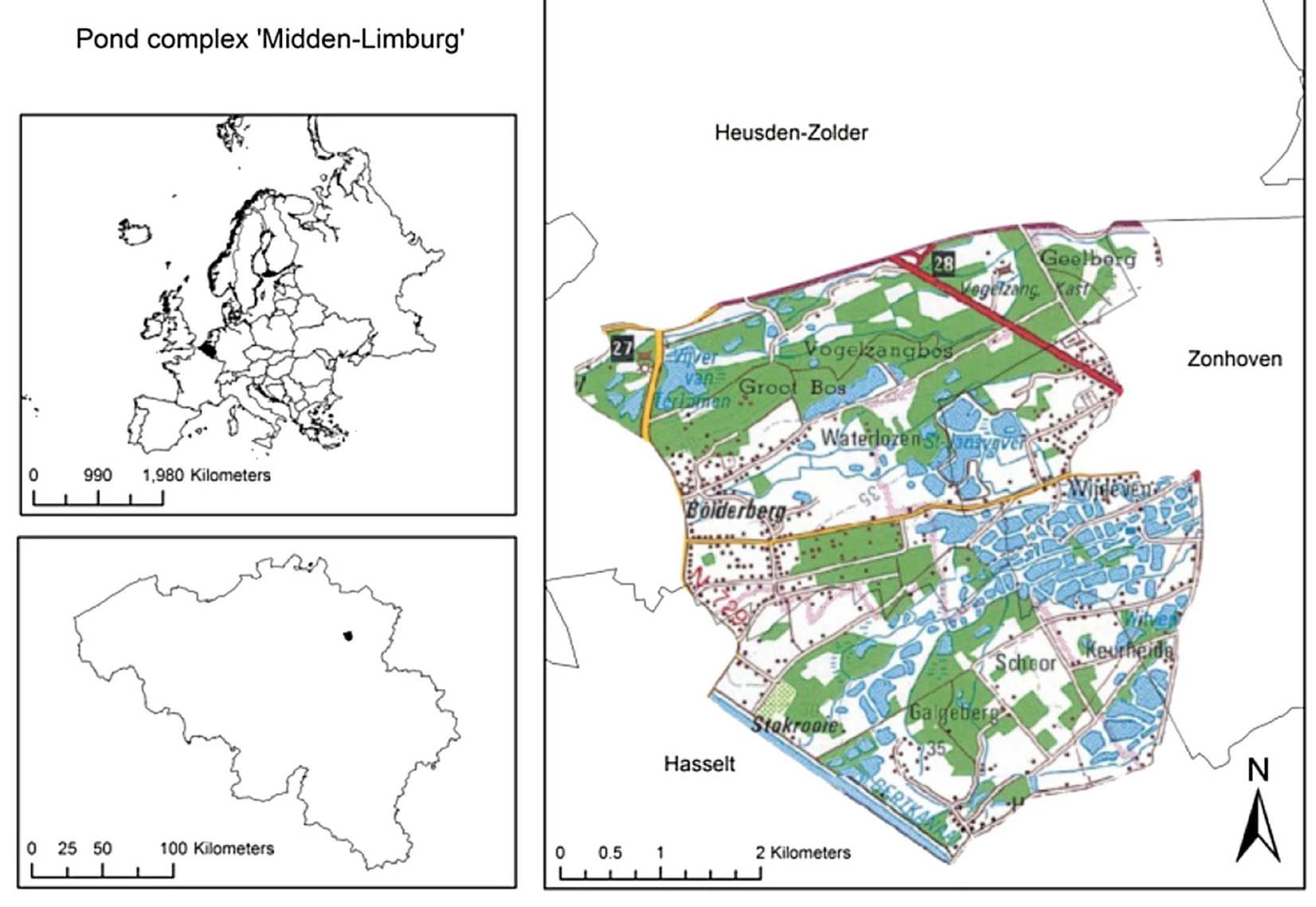

Fig. 1. Pond complex 'Midden-Limburg', located in the North-East of Belgium, in West-Europe. 
area. The pond complex comprises more than 1000 shallow lakes and ponds of which many originate from the extraction of iron ore and peat (Lemmens et al., 2013). The area is well known for its high ecological values, which largely result from extensive management of the ponds during past decades. Recent intensification of fish farming activities has resulted in considerable ecological degradation of the ponds in the region and has led to an important loss of biodiversity. The present study focusses on ESS delivery of a single pond in this pond complex, using data for model development that were gathered from several ponds in the pond complex. For a detailed description of the study area, we refer to Lemmens et al. (2013).

The current pond management strategies in the region can be classified into three major types. A number of ponds are managed for purposes of nature conservation (NCM), some ponds are used for extensive fish farming (EFF) and an important number of ponds are used for intensive fish farming (IFF). Major differences among the considered management scenarios include the level of shoreline complexity, the initial stocking of fish (benthivores, planktivores and piscivores), the use of industrial fish feeds, and accessibility for recreational activities. In all management types, fish is harvested during pond drainage. Ponds that are managed for purposes of nature conservation are drained annually in autumn and refilled in early spring. After refilling, these ponds are stocked with low densities of planktivorous and benthivorous fish $\left(0-30 \mathrm{~kg} \mathrm{ha}^{-1}\right.$ year $\left.^{-1}\right)$. A considerable number of ponds under nature conservation management receive no fish stocking. Ponds in use for extensive fish farming are occasionally drained (approximately every two or three years) and are initially stocked with a moderate density of planktivorous, benthivorous and piscivorous fish (30-80 kg ha ${ }^{-1}$ year $\left.^{-1}\right)$. Additional fish feeds are not used in nature conservation management and extensive fish farming management. Ponds in use for intensive fish farming are annually drained in autumn and are stocked in spring with high densities of planktivorous and benthivorous fish $\left(100 \mathrm{~kg} \mathrm{ha}^{-1}\right.$ year $\left.^{-1}\right)$. Industrial feeds are used to increase fish production (approximately $1400 \mathrm{~kg} \mathrm{ha}^{-1}$ year $^{-1}$ ). Each management type has fixed and variable financial costs. Fixed costs basically comprise the costs related to the maintenance of the pond (e.g. reparation of dykes, silt removal, mowing of vegetation), whereas variable costs are closely related to fish stock management (stocking densities, industrial feeds, fish harvesting). The annual fixed management costs have been estimated to amount to $€ 778$, $€ 558$ and $€ 338$ per hectare for IFF, EFF and NCM, respectively (Lemmens, unpublished data).

\subsection{Selection of ecosystem services}

In the present study, the selection of ESS was based on the relevance of the services for the study area, whether or not their delivery can be altered by the considered management strategies, as well as on data and knowledge availability. Based on the CICES V4.3 classification (Haines-Young and Potschin, 2011), we selected six ESS that fulfilled all criteria: fish production, water quality regulation through nitrogen retention and four interlinked cultural services, including both use and non-use values. For a detailed overview of the selected services and their CICES classification, we refer to Table S1 in Supporting information. Aside from the cultural services, each ESS is assessed through a different indicator. The four selected cultural services were jointly assessed with a willingnessto-pay indicator per household (Hoyos, 2010). Supporting services, as defined by the MEA (2005), are not taken into account to avoid double counting. We note that we only considered one regulating service, whereas others may be of similar importance for the region (e.g. regulation of water quantity and avoidance of flooding; regulation of water quality besides nitrogen retention). This needs to be considered when interpreting the results. Biodiversity is also not included as an ESS in this study. Biodiversity is in part valued through the valuation of the cultural ESS. Nevertheless, outcomes of ESS studies should be complemented with biodiversity conservation aims to support final management decisions as only the utilitarian value of components of biodiversity can be inferred by ESS valuation (Swift et al., 2004).

\subsection{Model development}

\subsubsection{Bayesian belief networks}

A Bayesian belief network (BBN) is a multivariate statistical model that consists of two structural components: a causal network, often referred to as the directed acyclic graph (DAG), and conditional probability tables (CPTs) that quantify the relations in the graph. The DAG consists of a set of nodes, representing the system's variables of interest, and a set of arrows, indicating the putative relationships between the system's variables. Each node has a finite set of states it can manifest. The beliefs to what extent its different states are realized are expressed through a probability distribution. The probability distribution of a node $\mathrm{X}$ is determined by the realized states of its preceding or parent nodes, using the conditional probability $\mathrm{P}(\mathrm{X} \mid$ parents $(\mathrm{X}))$, described in Bayes' theorem. These conditional probabilities are tabled in the model's CPTs and quantify the strengths of the relationships between the network's variables. For a detailed model description and statistical background we refer to Jensen (2001).

\subsubsection{Model development}

Model development was carried out according to the guidelines described by Marcot et al. (2006). First, an influence diagram was composed to describe the expected cause-effect flows of service provision of a single pond. We developed the causal network based on a consultation of researchers involved in ecological research in the study area. The quantification of the CPTs was mainly based on gained expert knowledge obtained from recent scientific research in the study area (e.g. Lemmens et al., 2013). When available, sitespecific empirical relations and site-specific data were preferred over expert knowledge to populate the model's CPTs, through Monte Carlo simulations and model learning, respectively. The spatial and temporal resolution considered for the model was one pond, with a water surface of one hectare, and one year, respectively. Model implementation was carried out in Netica (Norsys Software Corporation, 1998). To make sure the final model adequately reflected the system's functioning, the formerly consulted experts were confronted with a sensitivity analysis of the model. After evaluation and approval of the sensitivity analysis results, the model was converted into a Bayesian decision network (BDN) by adding a decision node, representing the different management scenarios, and a utility node, representing the sum of the monetary value of the provided services minus the management costs, for each management scenario. A schematic representation of the developed BDN is shown in Fig. 2. For a full representation of the operational model, see Fig. S1.

\subsubsection{Process description}

To populate the CPTs in the developed BBN, different knowledge sources were exploited, ranging from data and existing models to literature and expert knowledge. This section briefly discusses the development of all components of the network, including scenario definition, fish production modeling, cultural value modeling and nitrogen retention modeling. More details on the types of knowledge used in each submodel and technical details related to model implementation can be found in the Supporting Information (Appendix S1). 


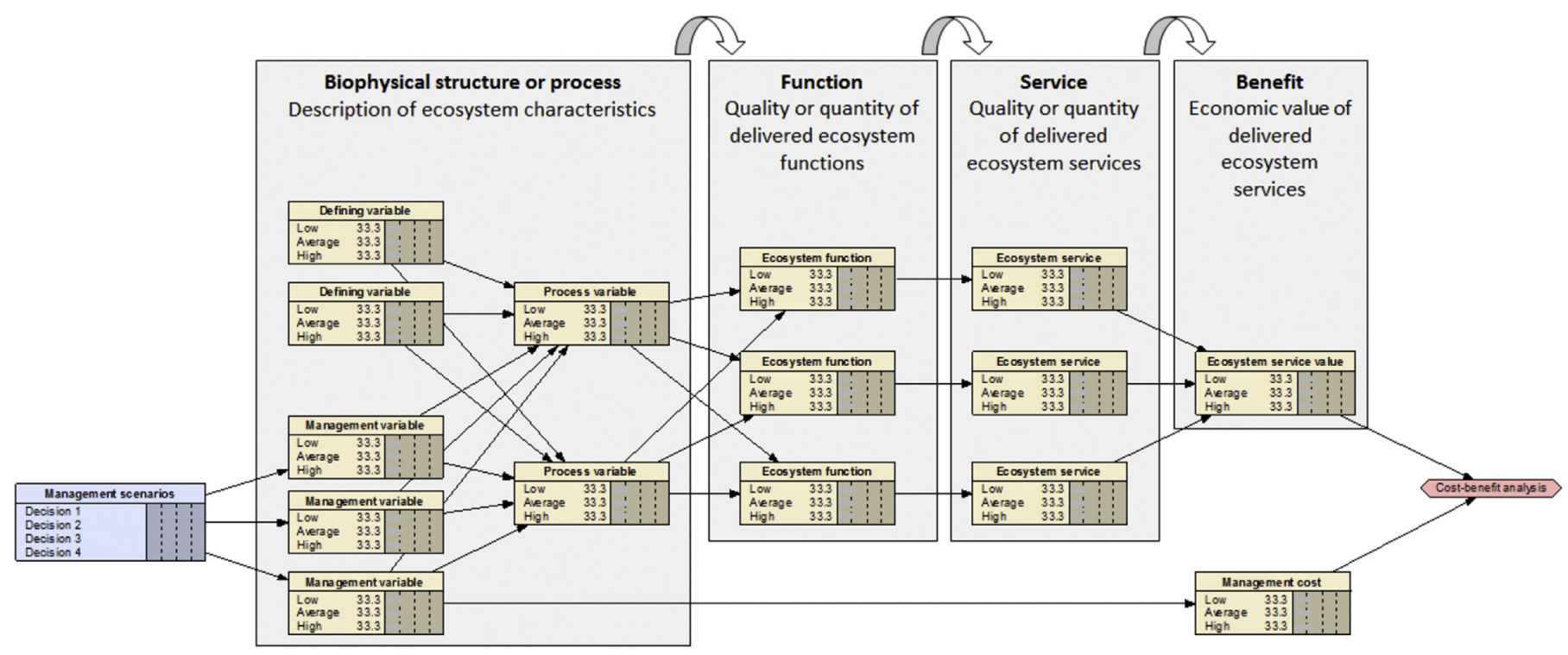

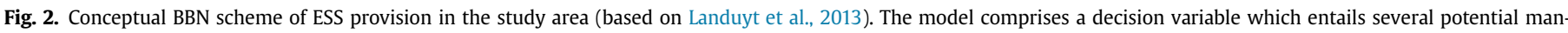

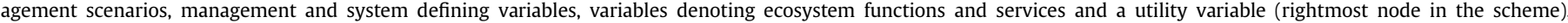

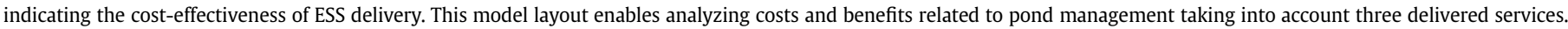

2.3.3.1. Management scenarios. A decision node was implemented in the model to evaluate and compare the considered scenarios in terms of ESS delivery and management costs. This node, in which each management scenario is represented as a separate state, was coupled with the manageable variables to represent the influence of management on these variables. Fig. 3 illustrates how the considered scenarios were implemented in the BBN.

2.3.3.2. Fish production. Fish farming activities in the area comprise the production of a broad range of fish species. The effect of fish stocking and the use of fish feeds on fish production, was determined based on empirical data from previous research in the study area (Lemmens, unpublished data) and on knowledge obtained from local fish farmers. We assumed a ten-fold biomass increase for benthivorous fish with additional feeding (based on fish farmer experiences) and a one point five-fold increase for all functional fish groups without the use of feeds (based on scientific experiments). The economic valuation of fish production is based on current market prices derived from face-to-face interviews with local fish farmers. Although prices can show some variation among years and with fish body size, we assumed fixed market prices of $€ 4 \mathrm{~kg}^{-1}$ for benthivorous and planktivorous fish and $€ 10 \mathrm{~kg}^{-1}$ for piscivorous fish. In addition to these benefits, also fixed and variable managements costs were taken into account (discussed in section 2.1). The cost of providing additional feeding was derived from interviews with local fish farmers.

2.3.3.3. Cultural services. The cultural value people attach to improvements in the ecological status and accessibility of the ponds in the study area was determined using a stated preference choice experiment (CE) (Hoyos, 2010; Liekens et al., 2013; De Valck et al., 2014). Biodiversity, water quality, shoreline complexity and accessibility of the pond were the main variables included in the choice experiment. Another important variable was distance to the pond complex. This variable allows defining a market extent without the use of artificial boundaries (Liekens et al., 2013). As the willingnessto-pay of the valuation function converged to zero for travel distances above $1 \mathrm{~km}$, the market was limited to the households living in a $1 \mathrm{~km}$-buffer around the study area (Fig. 1). The obtained WTPformula summarizes a respondent's household's willingness to pay for quality improvements of a single pond (1 ha) (Table 1, Eq. (1)).

The total cultural value of the pond was obtained by multiplying the average WTP per household with the number of households within the market extent. Assigning a larger value to the size attribute, to estimate the total WTP for the entire pond complex for example, would result both in a larger market extent and a higher WTP per household. Note that, in this case, the total WTP will be substantially higher compared to the result of multiplying the total WTP for a single pond with the total number of ponds in the complex.

As the WTP depends on pond biodiversity and water quality, both aspects as well as their determining processes, were included in the model. These determining processes were modeled based on general expert knowledge, gathered through an online expert questionnaire (method adapted from Pollino et al., 2007).

2.3.3.4. Nitrogen retention. Nitrogen retention in the pond system was approximated by summing nitrogen assimilation in fish biomass and denitrification of nitrogen in the water column. $\mathrm{Ni}$ trogen assimilation in fish biomass was derived from the modeled fish biomass gain based on an average fish nitrogen content of $2.6 \%$ (Ramseyer, 2002). Denitrification in the water column depends on retention time and pond depth, and was modeled based on a regression formula derived from a meta-analysis performed by Seitzinger et al. (2006). This formula predicts percentage nitrogen removal based on retention time and pond depth (Eq. (2)).

$\mathrm{NN}_{\text {removed }}(\%)=88 \cdot \frac{\text { Water depth }(\mathrm{m})^{-0.368}}{\text { Residence time }(\text { year })}$

To value nitrogen removal, we made use of the avoided abatement cost, a valuation method suggested by Broekx et al. (2013) for valuation of nitrogen removal in surface waters in Flanders, Belgium. As local estimates for the study area were not available, we made use of a high $\left(€ 74 \mathrm{~kg}^{-1} \mathrm{~N}\right)$ and a low $\left(€ 5 \mathrm{~kg}^{-1} \mathrm{~N}\right)$ estimate for the entire Flemish region (Cools et al., 2011). To instantiate this 

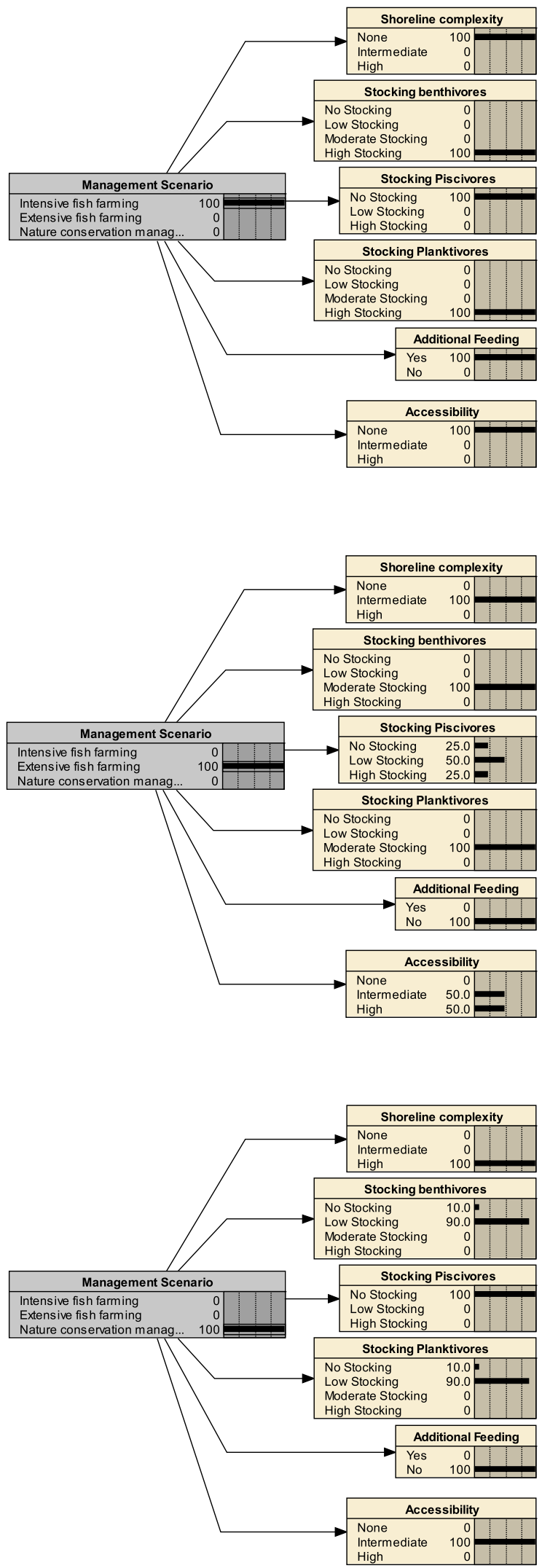

Fig. 3. The implementation of the management scenarios and their relative influence on the individual management variables: additional feeding, stocking of planktivores, stocking of piscivores, stocking of benthivores, accessibility and shoreline complexity. input node in the network, we made use of a uniform distribution over the entire range of the interval.

\subsection{Qualitative and quantitative analysis of model results}

\subsubsection{Qualitative assessment of model results}

A qualitative assessment of the model results is carried out based on the intermediary ESS production nodes in the BBN. These nodes express ESS production in biophysical terms $\left(\mathrm{kg} \mathrm{ha}^{-1} \mathrm{y}^{-1}\right)$, with the exception of the ESS cultural value, which is measured directly in monetary terms $\left(€ \mathrm{ha}^{-1}\right.$ year $\left.^{-1}\right)$. As aggregation of these biophysical quantities per scenario is not possible, we normalized each service between no production (0\%) and maximum production $(100 \%)$ and compared them in radar plots for each management scenario. This way, ESS delivery can be compared qualitatively among the considered scenarios.

\subsubsection{Quantitative assessment of model results}

As uncertainties were taken into account to estimate the monetary value of each delivered service, a probabilistic cost-benefit analysis was carried out for each scenario. In a probabilistic environmental CBA, uncertainties associated with ESS delivery are taken into account, while monetary values are used to express the relative importance of the individual ESS. To visualize probabilistic CBAs, cumulative probability distribution functions $\left(\mathrm{CDF}_{\mathrm{X}}\right)$ are frequently used (Karmperis et al., 2012). CDFs can be easily derived from discrete probability distributions $\left(P_{X}\right)$ (Eq. (3)).

$\mathrm{CDF}_{X}(x)=P(X \leq x)=\sum_{i=0}^{x} P_{X}(i)$

The slope of a CDF visualizes the uncertainty associated with the outcome of a particular scenario. Steep curves denote low uncertainty, while flat curves denote high uncertainty. The position of the curve indicates the profitability of a particular scenario. Scenarios are considered more profitable the more right their curves are located.

To test the model's sensitivity to the selected set of ESS, the model was ran several times considering three different sets of ESS: considering only fish production as a relevant ESS, considering both fish production and cultural services, and taking into account all three services. These three sets were composed in accordance with the spatial distribution of the ESS beneficiaries ranging from local fish farmers to regional citizens.

\subsubsection{Sensitivity analysis}

To analyze the sensitivity of the model output and the importance of each individual variable, we performed a sensitivity analysis. This analysis provides useful information on the importance of each variable and its associated CPTs. The sensitivity analysis is carried out with the Netica software (Norsys Software Corporation, 1998). For a detailed description of sensitivity analysis in Netica, we refer to Marcot (2012).

\section{Results}

\subsection{Qualitative and quantitative assessment of ecosystem service delivery}

The radar plots in Fig. 4 qualitatively represent ESS delivery under the three considered management strategies. The expected ESS delivery is positive under all management scenarios, with only nitrogen retention being slightly negative under IFF management. This indicates that intensively managed ponds discharge more nitrogen through their effluent than they have received from 
Table 1

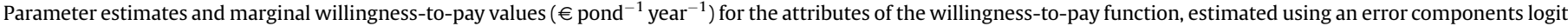
model.

\begin{tabular}{|c|c|c|c|}
\hline Attributes and interactions & Model result & WTP & Confidence interval \\
\hline Price & $-0.01465^{c}$ & 1 & \\
\hline Average shoreline complexity & $0.197627^{\mathrm{b}}$ & 0.006751 & $0.003547 ; 0.010966$ \\
\hline High shoreline complexity & $0.217357^{c}$ & 0.007425 & $0.004088 ; 0.01174$ \\
\hline Limited availability of walking trails & $0.435792^{\mathrm{c}}$ & 0.014888 & $0.009788 ; 0.023816$ \\
\hline Full availability of walking trails & $0.387062^{c}$ & 0.013223 & $0.008468 ; 0.020896$ \\
\hline Average species richness & $0.313036^{c}$ & 0.010694 & $0.006663 ; 0.017144$ \\
\hline High species richness & $0.323459^{c}$ & 0.01105 & $0.006848 ; 0.017536$ \\
\hline Good water quality & $0.859976^{c}$ & 0.029379 & $0.020526 ; 0.045707$ \\
\hline Very good water quality & $1.006895^{\mathrm{c}}$ & 0.034398 & $0.023729 ; 0.054184$ \\
\hline Size (ha) & $0.001776^{\mathrm{a}}$ & 1 & \\
\hline Distance $(\log (\mathrm{km}))$ & -0.14722 & -10.0475 & $-14,8277 ;-5.2664$ \\
\hline Income $(€)$ & $0.000588^{\mathrm{c}}$ & 0.0000201 & $0.0000128 ; 0.0000309$ \\
\hline Member of nature organization (\%) size (ha) & $1.878517^{c}$ & 0.064175 & $0.03889 ; 0.10187$ \\
\hline
\end{tabular}

a $10 \%$ Confidence level.

c $1 \%$ Confidence level.

inflowing water. NCM and EFF seem to be associated with the most balanced and optimal ESS delivery when each of the ESS are considered to be equally important. Fig. 4 additionally suggests complementarity between IFF at the one hand and EFF and NCM at the other hand due to a clear trade-off between fish production and the other two considered services. This qualitative assessment does not provide information on the relative importance of each service, nor on the management costs or uncertainties associated with the delivery of ESS.

\subsection{Monetary assessment of ecosystem service delivery}

The probabilistic results of the CBA, considering all three ESS, are shown in Fig. 5a. As can be seen in the plot, the curve of the NCM scenario is located rightmost. Or, in other words, NCM seems to be the most profitable scenario. The curves of the IFF and EFF scenario cross each other, indicating less clear differences in profitability among these scenarios. Under the current selection of ESS, both the expected net benefit and the probability of a positive net benefit will be higher for NCM. Taking into account uncertainties, IFF can be seen as a management practice associated with high risks. The risks associated with the expected net benefit of EFF and NCM are lower. NCM can be considered as a low risk investment. Note that the uncertainty in the model output should be seen as a minimum estimate, as not all uncertainties are known and documented and, thus, integrated in the model.
Fig. 5b and c illustrates the effect of taking into account fewer services. In case only fish production is considered as a relevant service, the IFF scenario stochastically dominates all other scenarios and, thus, would be considered the most profitable. Both the probability of achieving a positive net outcome (intersection of the curve with the vertical line) as the probability of achieving high benefits is higher for IFF than for the other management types. When the cultural value is additionally taken into account, the curves converge, resulting in comparable expected net benefits for NCM and IFF (Fig. 5b). The low profitability of the EFF scenario is mainly caused by the high costs related to stocking of piscivores, a typical management practice in EFF. When all three services are taken into account, the curves switch position, denoting NCM as the most profitable scenario. Both the expected net benefit as the probability of a net positive outcome is higher for NCM under this more complete scenario.

\subsection{Sensitivity analysis}

Fig. 6 presents the top-ten most-influencing variables, determined by a sensitivity analysis of the model. As can be seen in this figure, all variables are related to the nitrogen retention process, which denotes that this process, and the way it is implemented in the model, can influence the outcome remarkably. Furthermore, none of the variables from which the CPTs were elicited by experts were listed, indicating that these variables were not of major importance for the model output. As their importance in the model
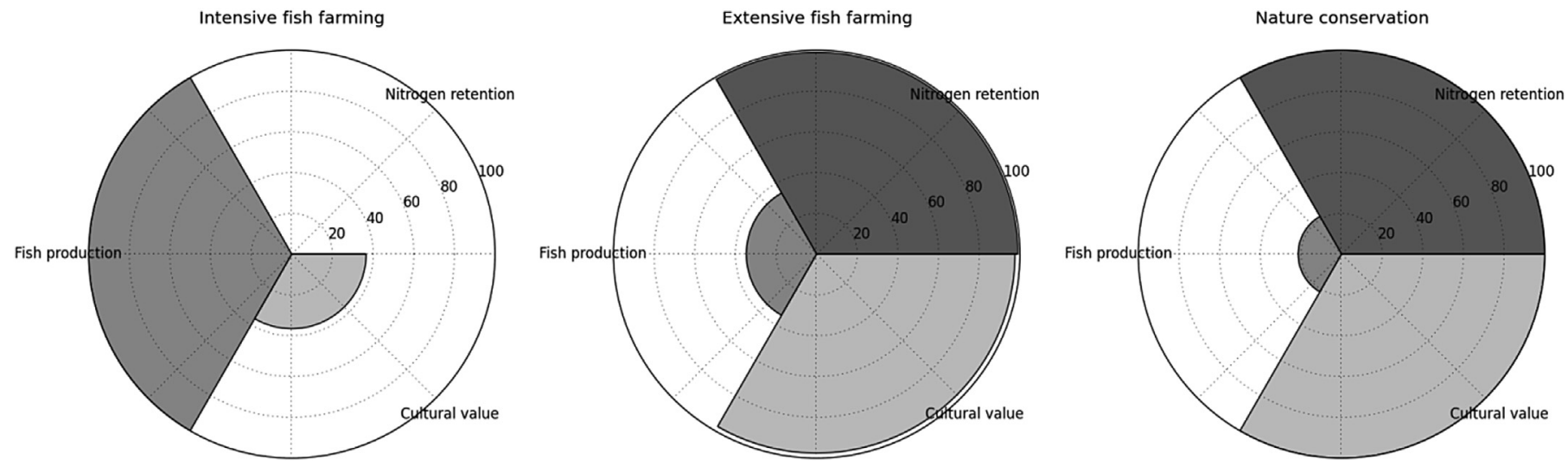

Fig. 4. Qualitative analysis of ecosystem service delivery under the considered management scenarios. 

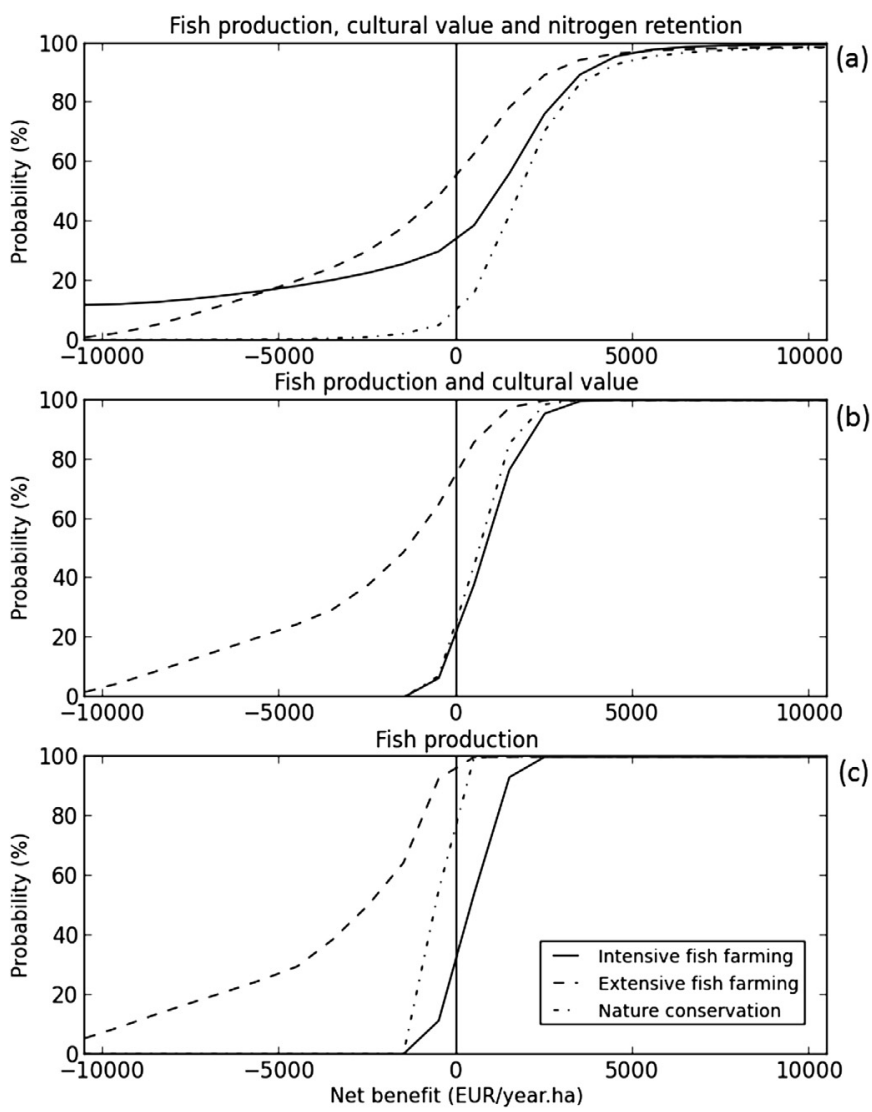

Fig. 5. Probabilistic cost-benefit analysis of the considered management scenarios considering three different sets of ecosystem services: fish production, cultural value and nitrogen retention (a), fish production and cultural value (b) and only fish production (c). These cumulative probability distributions of the BBN output visualize the probability of obtaining a lower net benefit than a particular value on the $x$-axes. The more right the curve, the more profitable the scenario, the steeper the curve, the more certain the expected net outcome of the scenario.

is rather low, approximate estimation of the CPTs of these nodes through expert elicitation should suffice. For this purpose, the survey definitely provided sufficient information.

\section{Discussion}

\subsection{Bayesian belief networks for decision support}

As stated by Landuyt et al. (2013), BBNs are valuable tools to assess ESS delivery in various contexts. Yet, several potentials of the modeling technique remain underutilized. Modeling the full cascade of ESS delivery using both decision nodes and utility nodes and structuring knowledge to integrate poorly-documented services with well-studied ones were mentioned as one of these underutilized potentials (Landuyt et al., 2013). This paper clearly illustrates the potential to integrate and structure knowledge from diverse scientific domains ranging from ecology (ecological processes) to economy (ESS valuation). Also the ability of BBNs to inform decision makers based on uncertainties and the added value of these uncertainties was demonstrated. Whereas management suggestions may be clear when based on expected outcome, they may be less clear when uncertainties are taken into account. Consideration of risks associated with the outcomes of management practices is especially useful when biological systems and financial markets, which are both inextricably linked with uncertainties, are considered in a CBA. In these situations, the relevance of conventional deterministic CBAs is limited.

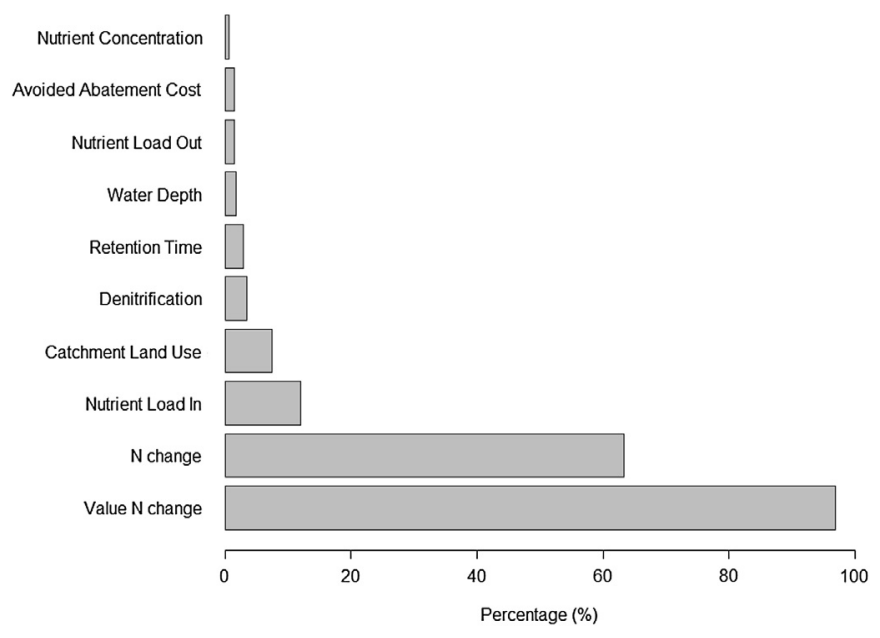

Fig. 6. Top-ten most-influencing variables derived from the sensitivity analysis. Percentage of variance reduction ( $X$-axis) specifies the reduction in variance of the output variable given information on the state of the node on the $y$-axis.

Yet, increased complexity is an important drawback of including uncertainties in the analysis. Although guidelines exist to support decision making based on probabilistic CBAs (Karmperis et al., 2012), end-users may encounter some difficulties interpreting them. Another important risk related to developing BBNs is using knowledge obtained from a limited amount of experts to draw general conclusions. One needs to consider that those conclusions then only reflect the beliefs of the consulted experts and not necessarily the truth.

\subsection{Limitations of the model: exclusion of ecosystem services}

Our results clearly demonstrate the risk of accounting only for a limited set of services. While discriminating among scenarios would reveal IFF as the most profitable management when only fish production is valued, broadening the set of services tipped the balance toward more nuanced and even qualitatively opposite results. The fact that different sets of ESS can change management suggestions stresses the need to try to consider a complete or balanced as possible set of delivered ESS for evaluating alternative management practices and that ignorance of poorly studied services entails an important risk for biased recommendations that may be both qualitatively and quantitatively wrong. Considering the fact that we have only included one regulatory service in our analysis, while others (e.g. water retention) may be important as well, we expect the model results to change considerably when including more regulatory services. Based on findings of previous research on the relationship between biodiversity and delivery of regulating ESS (e.g. Balvanera et al., 2006), we expect that taking into account additional regulating services would promote NCM as the most profitable scenario. Although this indicates that the presented model results cannot be seen as providing final management suggestions, we believe that the model has the potential to contribute to more complete ESS assessments as both well-studied (based on empirical data) and poorly-studied services (merely based on qualitative data) can be taken into account in BNNs. Due to their modular nature, BBNs can be easily expanded to include more services when more information becomes available.

\subsection{Limitations of the model: upscaling and spatial configuration}

As suggested in the methods section, considering the entire pond complex will probably lead to completely different outcomes 
for the cultural values compared to multiplying the total economic value of one pond with the total number of ponds in the complex. The inability to use the model to assess ESS delivery of the entire pond complex is therefore a second important limitation of our current analysis. The causal relations in the BBN, derived for a single pond, cannot be blindly extrapolated to multiple ponds. The number of ponds and their spatial configuration will have an effect on ESS, such as nitrogen retention and regulation of water quality in general. Biodiversity, for example, would benefit from a combination of different pond management types (Oertli et al., 2002; Scheffer et al., 2006; Lemmens et al., 2013), a result that is not predictable with a model based on one pond. Upscaling of WTP values encounters similar difficulties. As the survey considered only uniform changes in one pond or similar changes in 50 ponds, we cannot predict people's preference for particular mosaic scenarios. Further research on this is needed, including identification of spatial interactions among ponds and assessing the cultural and ecological value of mosaic scenarios.

\subsection{Monetary valuation of ecosystem services}

Applying monetary valuation in ESS assessment has both advantages and disadvantages (Gómez-Baggethun and Ruiz-Pérez, 2011). An important advantage is the ability to aggregate the delivery of multiple services in a common indicator which is understandable for a broad range of stakeholders. Moreover, aggregation of ESS delivery to one monetary value enables consideration of management costs which, in turn, enables analyzing costeffectiveness of management practices. Although monetary valuation in many cases can deliver clear and explicit results, some disadvantages of monetary valuation need to be mentioned. As stated by Martín-López et al. (2013), there is a bias toward provisioning services. However, while the economic benefits of fish production are the easiest to quantify, only a limited set of stakeholders benefit from them. Given the negative relationship between intensive fish production and biodiversity (Lemmens et al., 2013) and regulatory services (this manuscript, Balvanera et al., 2006), this high yield for a limited number of stakeholders comes at a cost for a broader set of stakeholders. This cost is, however, more difficult to quantify as regulatory services in general are more difficult to assess in monetary terms. Moreover, monetary valuation is not well-designed to quantify the intrinsic value of nature, which therefore needs to be considered aside from the economic analysis of management practices. Blinded by the strength of an economic analysis, assessing the effects on biodiversity is frequently forgotten.

\section{Conclusion}

Putting the ESS approach into practice and accounting for uncertainties are important challenges for sustainable management of ecosystems. The proposed methodology to assess multiple management practices shows that both are feasible. Compared to conventional CBAs, the suggested approach of BBNs can offer valuable information on uncertainties associated with environmental management. In addition to the added value of uncertainties, the benefits of an ESS approach to provide guidelines for management of water bodies are clearly demonstrated in this study. The key challenge is, however, that many ESS remain difficult to quantify as their valuation often requires a lot of data. As a result, they risk to be ignored in many assessments. Our analysis clearly shows that inclusion or ignorance of specific ESS strongly affects the model results and the recommendations that can be drawn from them. We acknowledge that our analyses too are still far from being complete. The added value of our analysis is that we at least managed to include three different types of ESS (one production, one regulatory and one cultural service), but we here did not yet deal with the multiple regulatory services nor with the spatial extent and configuration of the whole pond complex.

Overall, the here suggested ESS approach seems to be suitable for integrated environmental assessment. Nevertheless, the weaknesses of the ESS concept should not be ignored. For instance, due to the anthropocentric nature of the concept, the importance of biodiversity is frequently underestimated.

Although our study discusses an application of the ESS approach on a single freshwater pond for a limited set of services, the methods applied in this study can, in principle, be extrapolated toward other ecosystems and more services, provided that the necessary data are available. A lot of opportunities for BBNs exist for modelling ESS in a variety of systems and contexts. The challenge will be to avoid applying powerful approaches such as BBNs in a simplified or biased context.

\section{Acknowledgments}

This study was carried out within the ECOFRESH project funded by the Belgian Science Policy Office (BELSPO) (SD/TE/06). Additional work was carried out within a $\mathrm{PhD}$ research project funded by the Flemish Institute for Technological Research (VITO). Input from Ghent University was facilitated via the fund BOF09/24j/092.

\section{Appendix A. Supplementary material}

Supplementary material related to this article can be found at http://dx.doi.org/10.1016/j.jenvman.2014.06.015.

\section{References}

Atkinson, G., Mourato, S., 2008. Environmental cost-benefit analysis. Annu. Rev. Environ. Resour. 33, 317-344.

Balvanera, P., Pfisterer, A.B., Buchmann, N., He, J.-S., Nakashizuka, T., Raffaelli, D., Schmid, B., 2006. Quantifying the evidence for biodiversity effects on ecosystem functioning and services. Ecol. Lett. 9, 1146-1156.

Barton, D.N., Saloranta, T., Moe, S.J., Eggestad, H.O., Kuikka, S., 2008. Bayesian belief networks as a meta-modelling tool in integrated river basin management-Pros and cons in evaluating nutrient abatement decisions under uncertainty in a Norwegian river basin. Ecol. Econ. 66, 91-104.

Bekefi, E., Varadi, L., 2007. Multifunctional pond fish farms in Hungary. Aquac. Int. $15,227-233$.

Bianchini, F., Hewage, K., 2012. Probabilistic social cost-benefit analysis for green roofs: a lifecycle approach. Build. Environ. 58, 152-162.

Broekx, S., Liekens, I., Peelaerts, W., De Nocker, L., Landuyt, D., Staes, J., Meire, P., Schaafsma, M., Van Reeth, W., Van den Kerckhove, O., Cerulus, T., 2013. A web application to support the quantification and valuation of ecosystem services. Environ. Impact Assess. Rev. 40, 65-74.

Céréghino, R., Biggs, J., Oertli, B., Declerck, S., 2010. The ecology of European ponds: defining the characteristics of a neglected freshwater habitat. Pond Conserv. Europe 597, 1-6.

Cools, J., Broekx, S., Vandenberghe, V., Sels, H., Meynaerts, E., Vercaemst, P., Seuntjens, P., Van Hulle, S., Wustenberghs, H., Bauwens, W., Huygens, M., 2011. Coupling a hydrological water quality model and an economic optimization model to set up a cost-effective emission reduction scenario for nitrogen. Environ. Model. Softw. 26, 44-51.

Costanza, R., d'Arge, R., De Groot, R., Farber, S., Grasso, M., Hannon, B., Limburg, K., Naeem, S., O'Neill, R.V., Paruelo, J., 1997. The value of the world's ecosystem services and natural capital. Nature 387, 253-260.

Daily, G.C., 1997. Nature's Services: Societal Dependence on Natural Ecosystems. Island Press, Washington, DC.

De Valck, J., Vlaeminck, P., Broekx, S., Liekens, I., Aertsens, J., Chen, W., Vranken, L. 2014. Benefits of clearing forest plantations to restore nature? Evidence from a discrete choice experiment in Flanders, Belgium. Landsc. Urban Plan. 125, 65-75.

Downing, J.A., 2010. Emerging global role of small lakes and ponds: little things mean a lot. Limnetica 1, 9-24.

EPCN, 2007. Developing the pond Manifesto. Ann. Limnol. Int. J. Limnol. 43 $221-232$.

Gawne, B., Price, A., Koehn, J.D., King, A.J., Nielsen, D.L., Meredith, S., Beesley, L., Vilizzi, L., 2012. A Bayesian belief network decision support tool for watering Wetlands to Maximise Native fish outcomes. Wetlands 32, 277-287.

Gómez-Baggethun, E., Ruiz-Pérez, M., 2011. Economic valuation and the commodification of ecosystem services. Prog. Phys. Geogr. 35, 613-628. 
Gutiérrez-Estrada, J.C., Pulido-Calvo, I., de la Rosa, I., Marchini, B., 2012. Modeling inflow rates for the water exchange management in semi-intensive aquaculture ponds. Aquac. Eng. 48, 19-30.

Haines-Young, R., Potschin, M., 2011. Common International Classification of Ecosystem Services (CICES): 2011 Update. Tech. Rep.. European Environment Agency. URL: http://unstats.un.org/unsd/envaccounting/seeaLES/egm/Issue8a. pdf.

Hoyos, D., 2010. The state of the art of environmental valuation with discrete choice experiments. Ecol. Econ. 69, 1595-1603.

IUCN, 1997. Fishing for a Living: The Ecology and Economics of Fishponds in Central Europe. IUCN, Gland.

Jensen, F.V., 2001. Bayesian Networks and Decision Graphs. Springer, New York.

Karmperis, A.C., Sotirchos, A., Aravossis, K., Tatsiopoulos, I.P., 2012. Waste management project's alternatives: a risk-based multi-criteria assessment (RBMCA) approach. Waste Manag. 32, 194-212.

Kloskowski, J., 2011. Differential effects of age-structured common carp (Cyprinus carpio) stocks on pond invertebrate communities: implications for recreational and wildlife use of farm ponds. Aquac. Int. 19, 1151-1164.

Landuyt, D., Broekx, S., D'Hondt, R., Engelen, G., Aertsens, J., Goethals, P.L.M., 2013. A review of Bayesian belief networks in ecosystem service modelling. Environ. Model. Softw. 46, 1-11.

Lemmens, P., Mergeay, J., De Bie, T., Van Wichelen, J., De Meester, L., Declerck, S.A.J. 2013. How to maximally support local and regional biodiversity in applied conservation? Insights from pond management. PloS One 8, e72538.

Liekens, I., Schaafsma, M., De Nocker, L., Broekx, S., Staes, J., Aertsens, J., Brouwer, R., 2013. Developing a value function for nature development and land use policy in Flanders, Belgium. Land Use Policy 30, 549-559.

Marcot, B.G., 2012. Metrics for evaluating performance and uncertainty of Bayesian network models. Ecol. Model. 230, 50-62.

Marcot, B.G., Steventon, J.D., Sutherland, G.D., McCann, R.K., 2006. Guidelines for developing and updating Bayesian belief networks applied to ecological modeling and conservation. Can. J. For. Res. 36, 3063-3074.

Martín-López, B., Gómez-Baggethun, E., García-Llorente, M., Montes, C., 2013. Trade-offs across value-domains in ecosystem services assessment. Ecol. Indic. 37, 220-228.

MEA, 2005. Ecosystems and Human Well-being: Synthesis. Millennium Ecosystem Assessment. Island Press, Washington DC.
Newton, A.C., Hodder, K., Cantarello, E., Perrella, L., Birch, J.C., Robins, J., Douglas, S., Moody, C., Cordingley, J., 2012. Cost-benefit analysis of ecological networks assessed through spatial analysis of ecosystem services. J. Appl. Ecol. 49, 571-580.

Norsys Software Corporation, 1998. Netica Application User's Guide. Norsys Software Corporation, Vancouver, BC, Canada.

Oertli, B., Joye, D.A., Castella, E., Juge, R.l., Cambin, D., Lachavanne, J.-B., 2002. Does size matter? The relationship between pond area and biodiversity. Biol. Conserv. 104, 59-70.

Pechar, L., 2000. Impacts of long-term changes in fishery management on the trophic level water quality in Czech fish ponds. Fish. Manag. Ecol. 7, 23-31.

Pollino, C.A., Woodberry, O., Nicholson, A., Korb, K., Hart, B.T., 2007. Parameterisation and evaluation of a Bayesian network for use in an ecological risk assessment. Environ. Model. Softw. 22, 1140-1152.

Ramseyer, L.J., 2002. Predicting whole-fish nitrogen content from fish wet weight using regression analysis. North Am. J. Aquacult. 64, 195-204.

Scheffer, M., Van Geest, G.J., Zimmer, K., Jeppesen, E., Sondergaard, M., Butler, M.G. Hanson, M.A., Declerck, S., De Meester, L., 2006. Small habitat size and isolation can promote species richness: second-order effects on biodiversity in shallow lakes and ponds. Oikos 112, 227-231.

Seitzinger, S., Harrison, J.A., Böhlke, J.K., Bouwman, A.F., Lowrance, R., Peterson, B., Tobias, C., Drecht, G.V., 2006. Denitrification across landscapes and waterscapes: a synthesis. Ecol. Appl. 16, 2064-2090.

Soto, D., Aguilar-Manjarrez, J., Brugère, C., Angel, D., Bailey, C., Black, K., Edwards, P. Costa-Pierce, B., Chopin, T., Deudero, S., Freeman, S., Hambrey, J., Hishamunda, N., Knowler, D., Silvert, W., Marba, N., Mathe, S., Norambuena, R., Simard, F., Tett, P., Troekk, M., Wainberg, A., 2008. Applying an ecosystem-based approach to aquaculture: principles, scales and some management measures. In: Soto, D., Aguilar-Manjarrez, J., Hishamunda, N. (Eds.), Building an Ecosystem Approach to Aquaculture. FAO, Rome, pp. 15-35.

Swift, M.J., Izac, A.M.N., van Noordwijk, M., 2004. Biodiversity and ecosystem services in agricultural landscape: are we asking the right questions? Agric. Ecosyst. Environ. 104, 113-134.

Ticehurst, J.L., Newham, L.T.H., Rissik, D., Letcher, R.A., Jakeman, A.J., 2007. A Bayesian network approach for assessing the sustainability of coastal lakes in New South Wales, Australia. Environ. Model. Softw. 22, 1129-1139.

UNEP/CBD, 2010. Available at: http://www.cbd.int/doc/decisions/COP-10/cop-10dec-02-en.pdf (accessed 21.03.13). 